\title{
Nouvelles études sur l'Ovide moralisé, Réunies et présentées par Marylène Possamaï Pérez
}

\section{Maria Colombo Timelli}

\section{(2) OpenEdition}

1 Journals

\section{Édition électronique}

URL : http://journals.openedition.org/studifrancesi/6192

DOI : 10.4000/studifrancesi.6192

ISSN : 2427-5856

Éditeur

Rosenberg \& Sellier

\section{Édition imprimée}

Date de publication : 1 novembre 2010

Pagination : $527-528$

ISSN : 0039-2944

\section{Référence électronique}

Maria Colombo Timelli, « Nouvelles études sur l'Ovide moralisé, Réunies et présentées par Marylène Possamaï Pérez », Studi Francesi [En ligne], 162 (LIV | III) | 2010, mis en ligne le 30 novembre 2015, consulté le 10 janvier 2021. URL : http://journals.openedition.org/studifrancesi/6192 ; DOI : https:// doi.org/10.4000/studifrancesi.6192

Ce document a été généré automatiquement le 10 janvier 2021.

\section{(c) 9 (i) $\Theta$}

Studi Francesi è distribuita con Licenza Creative Commons Attribuzione - Non commerciale - Non opere derivate 4.0 Internazionale. 


\title{
Nouvelles études sur l'Ovide moralisé, Réunies et présentées par Marylène Possamaï Pérez
}

\author{
Maria Colombo Timelli
}

\section{RÉFÉRENCE}

Nouvelles études sur l'Ovide moralisé, Réunies et présentées par Marylène POSSAMAÏ PÉREZ, Paris, Honoré Champion, 2009, pp. 265.

1 Résultat de deux journées d'études, ces contributions sont centrées sur le phénomène de la mutacion. Elles sont organisées en cinq sections, chacune inaugurée par quelques mots et une synthèse de M.P.P., qui donne aussi la bibliographie essentielle sur le sujet.

2 La première, «Enjeux théologiques et philosophiques de la notion de mutacion», s'ouvre par Les formes qui muees furent: figures et enjeux de la 'mutacion' dans l'OM d'Ana PAIRET (pp. 19-34). S'agissant de rendre les Métamorphoses d'Ovide compatibles avec la doctrine chrétienne, l'auteur de l'OM intervient sur la poétique du texte, et notamment sur l'analogie et les procédés métaphoriques, qui permettent de transformer la métamorphose en un changement d'apparence; sans proposer une théorie de la métamorphose, il agence différents discours, théologiques et philosophiques, qu'il met à profit dans sa réécriture pour parler de la perte et de la rédemption de l'homme.

3 Se fondant sur le traitement de la théorie de Pythagore sur la métempsychose, exposée dans le livre XV et escamotée par l'auteur de l'OM, Wagih AzZAM estime que celui-ci non seulement fait coexister les fables et la Bible, mais qu'il propose une leçon de tolérance qui n'exclut pas la tolérance religieuse, malgré la supériorité certaine de la religion chrétienne (Toute chose se change et mue, pp. 35-47).

4 Sébastien DOUCHET (La genèse entre création et 'mutacion'. Remarques sur l'OM et la pensée de saint Bonaventure, pp. 49-68) se concentre sur l'idée de la création et sur l'interprétation qu'en offre l'auteur de l'OM, très visiblement éclairé par la pensée de saint 
Bonaventure. S'il peut conserver la lettre de sa source, c'est parce que celle-ci contient déjà en germe l'interprétation chrétienne, et parce qu'il existe un progrès de la pensée au cours de l'histoire.

5 Deux articles sont réunis dans la section «Métamorphose et péché». Stefania CERRITO réfléchit d'abord sur quelques figures féminines et sur leurs transformations dans l'OM (Histoires de femmes, jeux de formes et jeux de sens, pp. 73-97). Si l'auteur médiéval voit dans le désir féminin, dans la passion sans bornes, un péché qu'il faut nécessairement châtier et anéantir, il ne renonce cependant pas à proposer des allégories positives même là où on ne s'y attendrait pas: ainsi pour Médée, devenue figure de Dieu, et pour Mirrha, figure de la Vierge et de Marie-Madeleine. Suit Cristina NOACCo (L'orgueil et la métamorphose dans l'OM: enjeux narratifs, poétiques et pédagogiques, pp. 99-119); après avoir dressé une typologie des comportements orgueilleux dans l'OM, elle reconnait un double procédé poétique: la métamorphose par analogie ou par opposition. Mais la punition nécessaire de l'orgueil n'exclut pas le rachat, toujours possible par le repentir et par le choix de l'humilité.

6 La troisième partie, "Esprit encyclopédique et cohérence», s'ouvre par un essai de Christine FERLAMPIN-ACHER, Les métamorphoses en plantes dans l'OM en vers: 'verges', 'flors' et 'floretes', pp. 125-142. Malgré les apparences, les métamorphoses ne sont pas traitées avec réticence par l'auteur médiéval; son discours tient compte de l'expérience quotidienne, mais a aussi recours au savoir encyclopédique. Selon Ch.F.-A. le végétal peut en outre garantir le lien entre la terre et le ciel, et représenter même des figures d'intercesseurs, voire le rôle de l'écriture, capable en l'occur-rence d'assurer le salut. Géraldine CHÂTELAIN (Une métamorphose sans fin? Le sort du monde incendié, pp. 143-161) lit ensuite le mythe de Phaéton, tel qu'il est interprété par l'auteur de l'oM, comme une véritable métamorphose: celle-ci concernerait la Terre, suspendue entre la Création et le Déluge d'une part, le Jugement dernier de l'autre.

7 La quatrième partie, «Réflexivité», comprend elle aussi deux contributions. La première est de Michèle GALLY (La poésie en métamorphose: quelques réflexions sur le -livre $V$ de l'OM, pp. 167-179): la glose proposée pour le mythe des Piérides, transformées en pies pour avoir osé rivaliser avec les Muses, permet de récupérer la fable comme signe de la fiction poétique; la poésie légitimée, la seule, est la poésie de la sagesse, poésie morale qui se nourrit en Dieu. Romaine wolf-Bonvin (L'art de disparaître-La métamorphose d'Arachné, pp.181-204, reproductions pp. 205-210) compare attentivement le -texte latin et la réfection française à la recherche des éléments qui fondent et justifient la glose si virulente réservée à la métamorphose d'Arachné. Dans une seconde partie, elle montre comment l'adjectif subtilis/subtil permet de récupérer les aspects positifs attestés aussi dans l'iconographie de certains manuscrits des Bestiaires, de l'OM et du Boccace, Des cleres et nobles femmes.

8 L'article de Virginie Minet-MAHY (De la poétique des Métamorphoses à la politique de la 'translatio' dans l'OM: l'image salvatrice, pp. 215-243) occupe seul la cinquième partie, Allégorie. Elle situe sa réflexion au croisement des deux logiques de la poétique des Métamorphoses et de la translatio. Une pre-mière section est consacrée à la figure du bœuf, métaphore de Moïse et du Christ, mais aussi topos que le Moyen Âge associe à la prédication. Suit une partie consacrée à l'opposition apparente de la doctrine de Pythagore et du mythe de Circée, conciliés dans la perspective qui mène du monde au Salut. 
9 Le volume est complété par un index des personnages mythologiques et bibliques (pp. 251-253), par l'index des auteurs et des ouvrages (anciens et médiévaux pp. 254-255, modernes p. 256; on se demande la raison de la précision 'les plus souvent cités', certains noms étant suivis d'un seul renvoi...), et par un index des notions (pp. 257-261). 